\title{
THE INCIDENCE OF PERFORATED APPENDICITIS AMONG PEDIATRIC PATIENTS IN KHARTOUM NORTH TEACHING HOSPITAL, SUDAN
}

\author{
Ibrahim Salih Elkheir ${ }^{1}$, Mohammed Altyb Alshykh², Ayman Gafer Mustafa ${ }^{3}$
}

\footnotetext{
${ }^{1}$ Consultant of paediatric surgery, head of the department of paediatric surgery in Khartoum North Teaching Hospital and associate professor of paediatric surgery Alzaiem Alazhari University -Sudan.

${ }^{2}$ MBBS, Alzaiem Alazhari University -Sudan.

${ }^{3}$ MBBS, Alzaiem Alazhari University -Sudan.

Corresponding author: $\underline{\text { dr.ibrahim5@hotmail.com }}$
}

\begin{abstract}
Introduction: Acute appendicitis is a common emergency condition in paediatrics with different ages. The perforated appendicitis is one of the most serious complications of acute appendicitis which may lead to peritonitis. The aim of our study is to calculate the incidence of perforated appendicitis. Methods: This is a retrospective cross-sectional study has been conducted at Khartoum north teaching hospital. The total number of patients was 214. Results: the most common age in this study are 13 years old and the mean age is 11 years, 128 of cases were male $59.8 \%$ and 86 were females $40.2 \%$. All cases of our study presented with fever $100 \%, 80.8 \%$ presented with right iliac fossa pain, and anorexia $100 \%$. $50.5 \%$ of cases came within the first day of presentation and $26.6 \%$ of cases came in $4^{\text {th }}$ day of presentation, all cases presented with right iliac fossa tenderness, $15.9 \%$ of cases presented with perforated acute appendicitis, $67.29 \%$ of cases operated after 6 hours, $5.61 \%$ operated in more than 6 hours and $27.1 \%$ operated after 6 weeks. Conclusion: In this study the incidence of perforated acute appendicitis was $15.9 \%$ which is low in comparison with another study because there was no delay in appendectomy operation and the majority of patients came within the first day of the disease.
\end{abstract}

Keywords: Incidence, Perforated Appendicitis, Paediatrics, Sudan. 


\section{Introduction}

Acute appendicitis is a common paediatrics surgical emergency, the admissions is about 1$2 \%$ of all paediatric surgical conditions (Almaramhy, 2017). The severity of acute appendicitis was classified as uncomplicated disease or complicated disease (perforated acute appendicitis, appendicular abscess) (Omling et al., 2019) or inflammatory mass (Guidaa et al., 2015). The diagnosis of this condition is challenging because of its symptoms are similar to another diseases such as gastroenteritis in which the patients presented with abdominal pain, vomiting nausea, diarrhea, or fever (Wang et al., 2019) . Or omental infarction(Yang, 2010) which presented with the same symptoms of acute appendicitis. The classic presentation of symptoms are not usual in children (Becker \& Bachur, 2007). The children have the higher rate of perforation, rather than the adults. (Jha et al., 2017) The rate of treated perforated appendicitis about $37 \%$ among children(Turela et al., 2019). In age of less than 5 years the rate of perforation is $30 \%$. The rate of missed and delayed diagnosis in older paediatrics about $28 \%$ to $57 \%$ (Çelik et al., 2019). The perforation is define as a fecalith in the abdomen or hole in the appendix (Peter et al., 2008 ). The delayed of treatment of acute appendicitis will lead to progression of the disease to perforation which can cause complications such as peritonitis, abscess and partial bowel obstruction and this complications increase the rate of morbidity and mortality (Ngim, 2014). The diagnosis of acute appendicitis by: 1-Clinical examination (GroseljGrenc et al., 2007), 2-Or by using imaging ; in the case of children we request abdominal ultrasound U/S rather than computed tomography CT scan but the uses of it is less due to risk of exposure to ionizing radiation (Phalke \& Das, 2018) 3-and other laboratory investigations such $\mathrm{C}$ - reactive protein CRP, white cell count and bilirubin (McGowan et al., 2013). The treatment of acute appendicitis are laparoscopic or open appendectomy. However, the role of laparoscopic appendectomy is controversial in management of complicated appendicitis in paediatrics (Tsai et al., 2012 ). In new study; uncomplicated acute appendicitis may treated non-operatively and the patients get the clinical recovery after received of antibiotics (Knaapen et al., 2019). Postoperatively all patients with perforated acute appendicitis must receive intravenous antibiotics for 5 days minimally. (St. Peter et al., 2008).

The aim of this study is to calculate the incidence of perforated appendicitis in Khartoum North Teaching Hospital.

\section{Methods}

This is a retrospective cross-sectional study at Khartoum North Teaching Hospital which is the one of reference hospital in Sudan and it placed in Bahri city. We was studied 214 patients who came with acute appendicitis which is one of the most common emergency condition in the paediatric surgery department. Some of the data were collected from the record of patients who were operated and some from new patients came to us then diagnosed as acute appendicitis cases and was operated. Duration of this study from November 2018 to August 2019. When the patients come to our emergency we take the history; assess and analyse the symptoms of acute appendicitis such as periumbilical pain, Right lliac Fossa pain (RIF), nausea, vomiting, anorexia, fever, dysuria and, changes of bowel habits and previous history of similar abdominal pain; and the duration of all this symptoms.

Then we do the examination; firstly general examination such as temperature, pulse rate... etc. secondly abdominal examination searching for RIF tenderness and rebound tenderness. Then we do the investigations like Complete Blood Count CBC, Urine analysis and sometimes we need to do imaging to support our diagnosis using abdominal ultrasound or computed tomography CT scan. And we followed our patients after the operation until get well then discharged them and must be followed in refer clinic. The data have been collected by questionnaires and was analysed by SPSS application. We was consent all new patients and explained to them all the information will be kept in privacy and consent the hospital for collect the data from records. 


\section{Results}

The most common age of cases were 13 years old which about $35.5 \%$ and the mean age is 11 years. $59.8 \%$ of cases are male and 86 are females $40.2 \%, 52 \%$ of cases came from alhag yousif city. $15.9 \%$ of cases presented with perforated acute appendicitis, $18.7 \%$ presented with appendiceal abscess, $27.1 \%$ presented with appendiceal mass and $38.3 \%$ presented simply to moderately inflamed appendix (Table 1 ). All cases of our study presented with fever $100 \%$, about $78 \%$ of cases presented with vomiting, $80.8 \%$ presented with right iliac fossa pain, $56.5 \%$ presented with periumbilical pain, $35.5 \%$ the pain shifted to the right iliac fossa but $64.5 \%$ of cases the pain was not shifted, $93.9 \%$ of cases have no history of similar abdominal pain. All cases presented with anorexia $100 \%$, $31 \%$ of cases presented with diarrhoea, $7.9 \%$ came with constipation and $77 \%$ of cases presented with no change in bowel habits (Table 2). All cases presented with RIF's tenderness, $58.9 \%$ of cases presented with rebound tenderness and the mean body temperature about 37.4 (17\%). $88.8 \%$ of cases were received samixone (ceftriaxone) and $6.1 \%$ of cases were received samixone and Diclofenac sodium injection. The mean TWBCS in our patients with perforated appendicitis was $18 \times 10^{3} / \mathrm{uL}(5.09 \%)$, mean platelets values $324.6 \times 10^{3} / \mathrm{uL}(91.65 \%)$ and mean hemoglobin value $11.5 \mathrm{mg} / \mathrm{dl}$ (3.26 \%) (Table 3 ). $50.9 \%$ of cases have been diagnosed without imaging, $40.2 \%$ of cases have been diagnosed with the US and $8.9 \%$ of cases have been diagnosed with CT scan (Table 4). $67.29 \%$ of cases operated within the first day of admission, $5.61 \%$ operated in the second day of admission and $27.1 \%$ operated after 6 weeks which explain the percentage of appendicular mass.

Table 1: Socio-demographic data of the cases and the types of acute appendicitis

\begin{tabular}{|l|c|c|}
\hline \multicolumn{1}{|c|}{ Variables } & N & $\%$ \\
\hline Age & & \\
\hline 9 years & 15 & 7.0 \\
\hline 11 years & 70 & 32.7 \\
\hline 12 years & 53 & 24.8 \\
\hline 13 years & 76 & 35.5 \\
\hline Gender & & \\
\hline Male & 128 & 59.8 \\
\hline female & 86 & 40.2 \\
\hline Types of appendicitis & & \\
\hline Simple to moderate & 82 & 38.3 \\
\hline Appendiceal mass & 58 & 27.1 \\
\hline Appendiceal abscess & 40 & 18.7 \\
\hline
\end{tabular}


Table 2: Symptoms of acute appendicitis

\begin{tabular}{|l|c|c|c|c|}
\hline Symptoms & \multicolumn{2}{|c|}{ Yes } & N & \\
\hline Anorexia & $\mathbf{N}$ & $\%$ & 0 & $0 \%$ \\
\hline Nausea & 214 & $100 \%$ & 127 & $59.3 \%$ \\
\hline Vomiting & 87 & $40.7 \%$ & 47 & $22.0 \%$ \\
\hline Fever & 167 & $78.0 \%$ & 0 & $0.0 \%$ \\
\hline Dysuria & 214 & $100.0 \%$ & 214 & $100.0 \%$ \\
\hline abdominal pain (RIF) & 0 & $0.0 \%$ & 41 & $19.2 \%$ \\
\hline periumbilical pain & 173 & $80.8 \%$ & 93 & $43.5 \%$ \\
\hline Shifting & 121 & $56.5 \%$ & 138 & $64.5 \%$ \\
\hline History of similar pain & 13 & $35.5 \%$ & 201 & $93.9 \%$ \\
\hline No history of similar pain & 201 & $6.1 \%$ & 13 & $6.1 \%$ \\
\hline Diarrhoea & 76 & $93.9 \%$ & 183 & $85.5 \%$ \\
\hline Constipation & 31 & $14.5 \%$ & 197 & $92.1 \%$ \\
\hline No change in bowel habits & 166 & $77.6 \%$ & 48 & $22.4 \%$ \\
\hline
\end{tabular}

Table 3: Findings on examination specific to acute appendicitis, Antibiotics was used and investigations

\begin{tabular}{|l|c|c|}
\hline \multicolumn{1}{|c|}{ Variables } & N & $\%$ \\
\hline Sings & & \\
\hline RIF tenderness & 214 & $58.9 \%$ \\
\hline Rebound tenderness & 126 & Std. deviation= $0.42465(17 \%)$ \\
\hline $\begin{array}{l}\text { Body temperature } \\
\text { (mean) }\end{array}$ & $37.4 \mathrm{C}$ & \\
\hline Antibiotics & 190 & $88.8 \%$ \\
\hline $\begin{array}{l}\text { Samixone } \\
\text { (Ceftriaxone) }\end{array}$ & 11 & $5.1 \%$ \\
\hline Diclofenac sodium & 13 & $6.1 \%$ \\
\hline samixone and vortrine & & \\
\hline Investigations & $18 \times 10^{3} / \mathrm{uL}$ & Std. deviation (3.70839) \\
\hline TWBCs mean & $11.5 \mathrm{mg} / \mathrm{dl}$ & Std. deviation (1.44201) \\
\hline Haemoglobin mean & $324.6 \times 10^{3} / \mathrm{uL}$ & Std. deviation (112.60253) \\
\hline Platelets & & \\
\hline
\end{tabular}


Table 4: Type of Imaging done to patients

\begin{tabular}{|l|c|c|}
\hline \multicolumn{1}{|c|}{ Imaging } & N & $\%$ \\
\hline No imaging & 109 & $50.9 \%$ \\
\hline Ultrasound scan the US & 86 & $40.2 \%$ \\
\hline $\begin{array}{l}\text { A computed tomography } \\
\text { CT scan }\end{array}$ & 19 & $8.9 \%$ \\
\hline
\end{tabular}

\section{Discussion}

Appendicitis is an acute inflammatory disease may result from obstruction of the appendix lead to inflammation, perforation and necrosis.(Veli Avci, 2019 ).It is a one of the commonest surgical emergency in adults or paediatrics.(Aneirosa et al. , 2019). We were conducted this study in Khartoum North Teaching Hospital which is a one of the reference hospital in Sudan which located in Bahri city and contain one of the referral centre of the paediatric surgery in the Sudan. Highest incidence in of acute appendicitis in our study were in males rather than females but both at the similar age 11-13 years old and the mean age 11 years ( Becker \& Bachur, 2007). The symptoms of acute appendicitis in our study were RIF pain which was less in percentage than previous studies 94\%(Ngim, 2014) because of some cases were came to us before shifted of the pain to RIF, the percentage of vomiting, absence of changed in bowel habits, tenderness and rebound tenderness in RIF near to percentage in previous studies (Ngim, 2014; Becker \& Bachur, 2007). 50.5\% of cases were came within the first day to our paediatric surgery emergency. The diagnosis of cases in our department depend on clinical examination so $50.9 \%$ diagnosed without imaging just $40.2 \%$ diagnosed by US. Another investigations that we were did; Complete
Blood Count $\mathrm{CBC}$ and found that TWBCs was high and the mean value was $37.4(17 \%)$ which similar to another studies ( McGowan et al., 2013) (Groselj-Grenc et al., 2007) (Yang et al., 2010). In our study $88.8 \%$ of patients received antibiotic (ceftriaxone) before and after the operation. In recent study $15.9 \%$ of cases presented with perforated acute appendicitis and it's low in compare with other study which the rate of perforation about $52 \%$ ( Ngim et al., 2014) because we operate all patients whom diagnosed with acute appendicitis without delay in time of operation and almost cases operated within the first day of admission (Papandria et al., 2013)

\section{Conclusion}

The incidence of perforated acute appendicitis was $15.9 \%$ which is low in our study in comparison with the previous study because there was no delayed in appendectomy operation in our department and the majority of patients come within the first day of the disease. That means the delayed operation increases the risk of perforated appendicitis.

\section{Conflict of interest}

No one of authors has a conflict of interest. 


\section{References}

Almaramhy, H. H. ( 2017). Acute appendicitis in young children less than 5 years: review article. Almaramhy Italian Journal of Pediatrics, 43(15).

Aneirosa, I. C., Araceli Garcíaa, Pedro Yustea , Eduardo Ferreroa , Andrés Gómeza. (2019). pediatric appendicitis: age does make a difference. Rev Paul Pediatr, 1-7.

Becker, T \& Bachur R. (2007). Atypical Clinical Features of Pediatric Appendicitis. ACADEMIC EMERGENCY MEDICINE, 14, 124-129.

Çelik, H. N., Mustafa Özçatal,Yasemin Altuner Torun. (2019). Role of neutrophil-to-lymphocyte ratio and platelet -to- lymphocyte ratio in identifying complicated appendicitis in the pediatric emergency department. Ulus Travma Acil Cerrahi Derg, 25(3), 222-228.

Guidaa, F. P., Massimo Di Graziab, Daniela Codricha, Maria Antonietta Lemboa, Maria Grazia Scarpaa, Waifro Rigamontia,. (2015). Perforated appendix with abscess: Immediate or interval appendectomy? Some examples to explain our choice. International Journal of Surgery Case Reports, 12, 15-18.

Groselj-Grenc, S. R., Dubravka Vidmar, Metka Derganc. ( 2007). Clinical and Laboratory Methods in Diagnosis of Acute Appendicitis in Children. Croat Med J, 48, 353-361.

Knaapen, J. H. v. d. L., Hugo A. Heij, Ernst L. W. van Heurn, Roel Bakx, Ramon R. Gorter. (2019). Clinical recovery in children with uncomplicated appendicitis undergoing non-operative treatment: secondary analysis of a prospective cohort study. European Journal of Pediatrics, 178, 235-242.

Jha K.K., S. S., Shruti Trehan, Gregory E Gilbert, Aisha Mohammed, Moon Hee Hur, Joseph Uricchio, Shama Shirazi, Pragya Jha and Romeen Lavani. (2017). Predictors of Perforated Appendix among Children. Jha et al., Pediatr Ther, 7(1). doi: 10.4172/2161-0665.1000310

McGowan,DR, H. M. S., Khawaja Zia, Mokthar Uheba and Irshad Ahammed Shaikh. (2013). The value of biochemical markers in predicting a perforation in acute appendicitis. ANZ J Surg, 83 79-83. doi: 10.1111/ans.12032

Ngim, K. F. Q., Amreeta Dhanoa, Joon Joon Khoo, Muthualhagi Vellusamy, and Chen Siew Ng. (2014). Pediatric Appendicitis in a Developing Country:
What are the Clinical Predictors and Outcome of Perforation? JOURNAL OF TROPICAL PEDIATRICS, 60, 409-414.

Phalke, Z. M., and Samrat Das,. (2018). Utilization of Imaging to Identify a Benign Condition Mimicking Acute Appendicitis in a Child. Journal of Investigative Medicine High Impact Case Reports, 6, 1-4. doi: 10.1177/2324709618797989

Papandria D, G. S., Rhee D, Salazar JH, Arlikar J, Gorgy A, Zhang Y, Abdullah F. (2013). Risk of perforation increases with delay in recognition and surgery for acute appendicitis. J Surg Res, 184(2), 723-729. doi: 10.1016/j.jss2012. 12.008. Epub 2012 Dec 27

Omling , M. S., S. Saluja , S. Bergbrant, L. Olsson, A. Persson, J. Björk and L. Hagander. (2019). Nationwide study of appendicitis in children. Wiley Online Library. doi: 10.1002/bjs.11298

Tsai ,C. S.-Y. L., Fu-Chen Huang (2012 ). Laparoscopic versus Open Appendectomy in the Management of All Stages of Acute Appendicitis in Children: A Retrospective Study. Pediatrics and Neonatology, 53, 289-294.

Turela, S. L. M., Mine Yuksela, Aysenur Ceylanc, Bilge Sumbul Gultepec. (2019). Perforated appendicitis in children: antimicrobial susceptibility andantimicrobial stewardship. Journal of Global Antimicrobial Resistance, 16, 159-161.

St. Peter, S. W. S., George W. Holcomb III, Daniel J. Ostlie. (2008). An evidence-based definition for perforated appendicitis derived from a prospective randomized trial. journal of Pediatric Surgery, 43, 2242-2245.

Veli Avci, K. A. (2019). Why is the rate of perforated appendicitis higher in girls in eastern Turkey, unlike the literature? Turk Pediatri Ars, 54(1), 40-43. doi:

10.14744/TurkPediatriArs.2019.82956

Wang, J. Y., Yu-shui Wang, Yan Liu,. (2019). Diagnostic accuracy of pediatric atypical appendicitis. Medicine, 98(13).

Yang , Y.-H. H., Mao-Meng Tiao, Kuo-Shu Tang , Fu-Chen Huang , Shin-Yi Lee (2010). Comparison of Clinical Characteristics and Neutrophil Values in Omental Infarction and Acute Appendicitis in Children. Pediatr Neonatol, 51(3), 155-159. 